months. The radiographic evaluation was carried out on an intention-to-treat basis on all of the patients who completed the combination period using hand and foot radiographs taken at baseline, and after 12 and 24 months. The reading was blindly performed by two radiologists using the 32-joint damage score (DS) of the Larsen-Dale method and the count of the eroded joints (EJC).

Results Seven patients discontinued the study therapy because of adverse events during the first period of the trial, and 18 patients prematurely withdrew, mainly because of lack of efficacy, during the second study phase. Using the last-observationcarried-forward method, the good or moderate responders according the EULAR criteria were $42(73.7 \%)$ at the end of the 6-month combination period, and $36(73.5 \%)$ at the end of the single agent phase. Overall, safety and tolerability was good. At baseline, the mean DS $( \pm$ SEM) in the CsA and MTX groups was respectively $5.1 \pm 1.5$ and $5.0 \pm 1.7$, and the mean EJC $( \pm$ SEM) was $1.1 \pm 0.3$ and $0.7 \pm 0.3$. The differences in the radiographic scores after 12 and 24 months were as follows. In the CsA group: DS12 month- $0=+7.3 \pm 3.2$, EJC12 month- 0 $=+2.1 \pm 1.1$, DS24 month $-0=+10.5 \pm 2.6(\mathrm{p}<0.01)$, EJC2 4 month $-0=+3.2 \pm 0.8$ ( $\mathrm{p}<0.01)$. In the MTX group: DS12 month- $0=+5.2 \pm 2.0$, EJC12 month $-0=+1.5 \pm 0.7$ $(\mathrm{p}=0.01)$, DS24 month- $0=+10.4 \pm 1.7(\mathrm{p}<0.01)$, EJC24 month- $0=+2.3 \pm 0.5(\mathrm{p}<0.01)$. The comparison between the two therapy groups did not show any significant difference. Conclusion Radiographic deterioration occurred in both treatment groups but was mild and slow. Combination therapy with CsA and MTX followed by single agent maintenance treatment seems to induce a persistent retardation of radiographic damage. Longer period of combination therapy could yield better control of the joint structural damage.

\section{FRI0058 PRESCRIPTION OF FOLIC ACID WITH METHOTREXATE IN RHEUMATOID PATIENTS: VARIATION AMONGST RHEUMATOLOGISTS IN WALES}

R Prasad, M De Silva. Rheumatology, Prince Charles Hospital, South Wales, UK

\subsection{6/annrheumdis-2001.1187}

Background Many rheumatologists would now consider methotrexate (MTX) as the disease modifying anti-rheumatic drug (DMARD) of choice in the treatment of rheumatoid arthritis (RA). Despite having the best efficacy-toxicity profile of the DMARDs, up to $30 \%$ of patients will discontinue treatment within the first year because of adverse effects.

The mechanism of toxicity remains unclear but folate metabolism is thought to play a part. Studies have shown that folic acid (FA) is superior to folinic acid in that high $(>10 \mathrm{mg} / \mathrm{wk})$ or low dose FA reduces gastroenterological toxicity by $80 \%{ }^{1}$ without loss of efficacy, and is cheaper than folinic acid. Haemotological toxicity is also more common in patients who have not received any folate supplementaion.

Various authors have suggested different FA regimes ${ }^{2,3}$ but there remains a lack of consensus on whether FA should be prescribed universally to patients taking methotrexate, whether it should be initiated only if side effects occur and what is the most effective regime?

Objectives To observe the variation in FA prescription amongst rheumatologists in Wales.

Methods A survey was conducted amongst all rheumatologists in Wales at consultant, specialist registrar, staff grade and clinical assistant levels, based at 11 district general hospitals and 1 University hospital. We asked if FA was prescribed routinely in all patients starting MTX; if so, what was the dose and frequency? If FA was prescribed daily, did it include the day of MTX administration?

Results Of the 35 rheumatologists contacted, there were 25 responses. 19 out of 25 prescribed FA routinely (76\%) when initiating MTX. $3(12 \%)$ did not prescribe FA routinely and 3 (12\%) sometimes prescribed FA.

14 out of 19 (74\%) who prescribed FA routinely used a dose of $5 \mathrm{mg} / \mathrm{wk}$ given 2-3 days after MTX. 2 (11\%) prescribed 5 $\mathrm{mg} /$ day, excluding the day of MTX; 1 (5\%) prescribed $10 \mathrm{mg} /$ wk; $1(5 \%)$ prescribed $5 \mathrm{mg}$ twice/wk; $1(5 \%)$ did not specify a dose. Of the 3 rheumatologists who sometimes prescribed FA, 1 used a dose of $5 \mathrm{mg} / \mathrm{wk}$; 1 prescribed $5 \mathrm{mg} /$ day, excluding day of and day after MTX; 1 prescribed $1 \mathrm{mg} /$ day, excluding day of MTX.

Conclusion Amongst 25 rheumatologists in Wales there are at least 6 variations in FA prescribing patterns, the most common regime being $5 \mathrm{mg} / \mathrm{wk}$ given 2-3 days after MTX. As there are no published guidelines, it would be reasonable to assume that the variation reflects the individual's personal preference and also reflects the lack of consensus.

We are now completing a further study comparing which of these regimes appears to be most effective in reducing adverse effects of MTX amongst RA patients newly started on therapy. The results of this study are expected in July 2001.

\section{REFERENCES}

1 Oritz Z, Shea B, Suarez-Alamazor ME, Moher D, Wells GA, Tugwell P. The efficacy of folic acid and folinic acid in reducing methotrexate gastroenterological toxicity in rheumatoid arthritis. A metanalysis of randomised controlled trials. I Rheumatol. 1998;25(1):36-43

2 Coleiro B, Mallia C. Toxicity profile of methotrexate in rheumatoid arthritis. A preliminary survey. Adv Exp Med Biol. 1999;455:359-65

3 Gutierrez-Urena S, Molina JF, Garcia CO, Cuellar ML, Espinoza LR. Pancytopenia secondary to methotrexate therapy in rheumatoid arthritis. Arthritis Rheum. 1996;39(2):272-76

\section{FRI0059 THE EFFICACY AND SAFETY OF PEGYLATED RECOMBINANT METHIONYL HUMAN SOLUBLE TUMOUR NECROSIS FACTOR RECEPTOR TYPE I (PEG STNF-RI; P55) IN A RANDOMISED, PLACEBO-CONTROLLED, CLINICAL STUDY OF PATIENTS WITH RHEUMATOID ARTHRITIS (RA)}

${ }^{1} \mathrm{M}$ Schiff, ${ }^{2} \mathrm{D}$ Furst, ${ }^{3} \mathrm{R}$ Fleischmann, ${ }^{4} \mathrm{M}$ Macri, ${ }^{5} \mathrm{~T}$ Joh, ${ }^{6} \mathrm{CK}$ Edwards, ${ }^{7} \mathrm{MW}$ Davis. ${ }^{1}$ Rheumatology, Denver Arthritis Clinic, Denver; ${ }^{2}$ Rheumatology, Virginia Mason Research Center, Seattle; ${ }^{3}$ Rheumatology, Metroplex Clinical Research Center, Dallas, USA; ${ }^{4}$ Clinical Affairs; ${ }^{5}$ Biostatistics; ${ }^{6}$ Inflammation, Amgen, Thousand Oaks; ${ }^{7}$ Clinical Research

\subsection{6/annrheumdis-2001.1188}

\section{Background}

Objectives PEG sTNF-RI was administered weekly for 12 weeks at 400 or $800 \mu \mathrm{g} / \mathrm{kg}$ vs placebo to assess efficacy and safety for the treatment of patients with RA.

Methods Subjects were randomised at 15 U. S. centres to receive PEG sTNF-RI or placebo (1:1:1). Subjects with disease duration of at least 6 months with $>=10$ swollen joints and $>=12$ tender/painful joints, and morning stiffness $>=45 \mathrm{~min}, \mathrm{C}$-reactive protein $(\mathrm{CRP})>=1.5 \mathrm{mg} / \mathrm{dL}$, or erythrocyte sedimentation rate $(\mathrm{ESR})>=28 \mathrm{~mm} / \mathrm{hr}$ were eligible for study. Subjects were allowed to continue most single or combination background DMARD therapies. If taking DMARDs, the doses must have been stable for 8 weeks before entry; only combination therapy 
involving methotrexate with sulfasalazine or hydroxychloroquine, or sulfasalazine plus hydroxychloroquine were allowed. Clinic visits occurred at baseline and weeks 1, 2, 4, 8, and 12 . Study related observations consisted of efficacy assessments, physical examination, laboratory assessments, adverse events (noninfectious adverse events and infectious episodes), concomitant medications, PEG sTNF-RI antibodies, and autoantibodies.

Results A total of 195 subjects were randomised and 194 subjects received $>=1$ dose of study drug. Efficacy: Subjects in the $800 \mu \mathrm{g} / \mathrm{kg}$ PEG sTNF-RI dose group had an ACR20 response rate of $50 \%$ which was significantly different $(\mathrm{p}=0.005)$ from the placebo group (26\%). TheACR20 response rate for the 400 $\mu \mathrm{g} / \mathrm{kg}$ group was $33 \%$ (NS vs. placebo). An increasing ACR20 response rate with increasing PEG sTNF-RI dose was detected at week 12 ( $\mathrm{p}=0.017)$. Treatment with $800 \mu \mathrm{g} / \mathrm{kg}$ PEG sTNF-RI resulted in statistically significant improvements in all individual ACR components except for swollen joint counts and CRP. Safety: No deaths or malignancies were reported. Two subjects experienced serious events; neither event was judged to be related to study drug or resulted in withdrawal from the study. The incidence of infectious episodes was slightly higher in subjects receiving PEG sTNF-RI (27\%) compared with subjects receiving placebo (21\%). Only the incidence of injection site reactions appeared to be treatmentÓrelated; (20\% PEG sTNFRI, $10 \%$ placebo). Noninfectious adverse events that occurred more frequently in PEG sTNF-RI subjects compared with placebo included diarrhoea ( $8 \%$ vs. $3 \%$ ), dizziness (6\% vs. $3 \%)$, and nausea (6\% vs. $3 \%)$. No PEG sTNF-RI treatmentÓrelated effects on laboratory variables, vital signs, or antibodies were evident.

Conclusion Weekly dosing with PEG sTNF-RI (400- or $800-\mu \mathrm{g}$ / $\mathrm{kg}$ ) for 12 weeks demonstrated a beneficial treatment effect in improving the signs and symptoms of subjects with RA. Treatment with PEG sTNF-RI appeared to be safe and well-tolerated. The type and incidence of adverse events was similar to those observed in clinical trials with other TNF- $\alpha$ inhibitors. Further patient exposure will be required to fully characterise the adverse event profile of PEG sTNF-RI in subjects with rheumatoid arthritis. Future studies will evaluate higher and more frequent dosing.

\section{FRI0060 SUCCESSFUL TREATMENT OF ACTIVE RHEUMATOID ARTHRITIS WITH CHIMERIC MONOCLONAL ANTIBODY TO TUMOUR NECROSIS FACTOR (INFLIXIMAB): AN OPEN STUDY}

KA Boki, VA Vassiliou, G Linardaki, HM Moutsopoulos. Department of Pathophysiology, National University of Athens School of Medicine, Athens, Greece

\subsection{6/annrheumdis-2001.1189}

Background Infliximab is a chimeric anti-tumour necrosis factor $\alpha($ anti-TNF $\alpha)$ monoclonal IgG1 antibody, neutralising the soluble cytokine and blocking the membrane bound cytokine that is used successfully for the treatment of active rheumatoid arthritis (RA) not controlled with other disease modified anti-rheumatic drugs (DMARDs).

Objectives The clinical evaluation of infliximab in the treatment of active RA.

Methods Twenty-four (24) patients (pts) with active RA (20 women and 4 men), mean age $46.4 \pm 10.17$ (years), and mean disease duration $9.9 \pm 7.77$ (years) received infliximab in a combination with Methotrexate $10 \mathrm{mg} /$ week and Prednizolone 7.5-
$10 \mathrm{mg} /$ day in an open unrandomized trial. Thirteen (13) pts completed three months therapy with infliximab and 11 pts six months. Infliximab was given at a dose of $3 \mathrm{mg} / \mathrm{kg}$ of body weight at week 0,2 and 6 of treatment protocol and then every 8 weeks. All these pts had received combination therapy with DMARDs for more than three months, before enrolling in the study, without sufficient improvement. Active RA was defined by 10 or more swollen joints $(10.9 \pm 4.7), 12$ or more tender joints $(13.4 \pm 5.11)$, ESR $>28 \mathrm{~mm}(48.0 \pm 19.23 \mathrm{~mm})$ and C-reactive protein $>5.0 \mathrm{mg} / \mathrm{dl}(37.4 \pm 12.69 \mathrm{mg} / \mathrm{dl})$. A statistical analysis was done after the third and sixth month of treatment.

Results At three months, the number of swollen joints was reduced to $3.3 \pm 2.73(\mathrm{p}<0.001)$ and the number of tender joints was, also, reduced to $4.1 \pm 3.17$ ( $\mathrm{p}<0.001$ ), ESR was $29.0 \pm 20.5 \mathrm{~mm}(\mathrm{p}<0.001)$ and CRP $18.6 \pm 13.05 \mathrm{mg} / \mathrm{dl}(\mathrm{p}$ $<0.001$ ). At six months, statistically significant difference was not observed in any of the parameters of disease activity: swollen joints were $2.8 \pm 2.01$ (NS), tender joints $5.6 \pm 4.3$ (NS), ESR $24.6 \pm 19.3 \mathrm{~mm}$ (NS) and CRP $15.4 \pm 12.3 \mathrm{mg} / \mathrm{dl}(\mathrm{NS})$. Four female pts were excluded from the study and the statistical analysis: one patient because of unsufficient respond, another patient because of allergic reaction during the 5 th infusion, and 2 pts because of uncontrolled urinary track infection after the $3 \mathrm{rd}$ infusion. All the pts declare dizziness, light headache, nausea, 2 pts reported abdominal pain after the first infusion and 2 pts increased hairing loss. One patient with alopecia areata universalis reported hair improvement but this result was only for a small period of time.

Conclusion The initiation of infliximab therapy in patients with active RA resulted in a fast and significant improvement of peripheral articular manifestations and quality of life. Even though major adverse events were not reported, the clinicians should be aware of this possibility.

\section{FRI0061 ANAKINRA ARRESTS JOINT DESTRUCTION IN PATIENTS WITH RA AND ESTABLISHED EROSIONS}

${ }^{1}$ B Bresnihan, ${ }^{2} \mathrm{D}$ McCabe, ${ }^{3}$ I Watt, ${ }^{4} \mathrm{H}$ Genant, ${ }^{2} \mathrm{~S}$ Robbins, ${ }^{2} \mathrm{RD}$ Newmark. ${ }^{1}$ Department of Rheumatology, St. Vincent's University Hospital, Dublin 4, Ireland; ${ }^{2}$ Clinical Development, Amgen Inc., Thousand Oaks, USA; ${ }^{3}$ Department of Radiology, University of Bristol, Bristol, UK; ${ }^{4}$ Department of Radiology, University of San Francisco, San Francisco, USA

10.1136/annrheumdis-2001.1190

Background Patients with active RA and manifest erosive disease (at least 1 joint erosion) are likely to develop further joint damage.

Objectives The aim of this study was to evaluate the effect of anakinra on progressive joint damage in patients with erosive disease.

Methods Serial radiographs were obtained during a 24 week randomised placebo controlled study of $30 \mathrm{mg}, 75 \mathrm{mg}$ or 150 $\mathrm{mg}$ anakinra daily. Joint damage was quantified using both the Larsen and modified Sharp methods (Genant A\&R, 41:1583, 98). Patients with at least 1 erosion at baseline were selected for study.

Results Approximately $75 \%$ of the 472 patients enrolled in the study had erosive disease (range $71-78 \%$ for each treatment group). The mean changes from baseline were highly significant for each anakinra dose group, when compared with placebo for reduction in the rate of joint destruction. The 75 and $150 \mathrm{mg}$ dose groups arrested joint destruction (no radiographic progression) in a higher proportion of patients compared with placebo. A dose response was observed with regard to both the mean 